\title{
Celebrating 8 projects that improved our world
}

\author{
Sharon E. Straus MD MSc, Chaidwick Leneis BA, Ian D. Graham PhD
}

$\infty \infty$

See related articles by Straus, by Moses and by Le May

I n October 2008, the Canadian Institutes of Health Research (CIHR) and CMAJ launched a competition to acknowledge top achievements in Canadian health research. These achievements had to have had "a significant impact on health, health care, and health research by improving our understanding of health and human diseases, tackling health challenges, and improving our health system."

Each year in Canada, over $\$ 6$ billion is spent on research and development in health. ${ }^{2}$ Of this amount, over $\$ 1$ billion comes from the public sector in the belief that we must move toward a knowledge-based society and that decisions about health and health care should be influenced in part by research. As a society, we understand that research requires stable funding. We also understand that it needs time to generate important breakthroughs, and even more time for these findings to lead to improvements in quality of care, the health care system and, ultimately, health outcomes. However, we often neglect to celebrate achievements in health research when they have made a difference.

Canadians can take pride in the role research from this country has played in advances in health care worldwide, including the discovery of insulin, the development of evidence-based medicine, and the discovery of the cystic fibrosis gene. Indeed, Canada is in the top 10 countries in terms of citation impact of publications in health sciences. ${ }^{3}$ It is time to celebrate achievements in Canadian health research and to congratulate our colleagues on their accomplishments.

We invited individuals or teams of health researchers, health professionals and others to submit original essays about significant achievements made in any area of health research. We did not scan the health sciences literature or funding databases to identify eligible achievements. Instead, we relied on people in research, practice and policy-making to identify relevant achievements for nomination. We did not limit the competition to research funded by the CIHR.

Applications were eligible if they described achievements in 1 of the following categories of research:

- Biomedical: Research with the goal of understanding normal and abnormal human functioning at the molecular, cellular, organ system and whole-body levels; developing tools and techniques to be applied for this purpose; and developing new therapies or devices to improve health or

\begin{abstract}
Key points
- The Canadian Institutes of Health Research and CMAJ launched a competition in October 2008 to acknowledge top Canadian achievements in health research.

- Eight awardees were chosen for their substantive impact on health, health care and health research in Canada and beyond.

- The next competition will be launched at the end of September 2009. We invite readers to nominate research achievements.

- In early 2010, we will post the $2009 / 10$ applications on the CMAJ website and invite readers to vote for their favourite achievement.
\end{abstract}

quality of life, to the point where they are tested on human subjects.

- Clinical: Research with the goal of improving the diagnosis and management of disease and injury; and improving the health and quality of life of individuals through all stages of life.

- Health services: Research with the goal of improving the efficiency and effectiveness of health professionals and the health care system through changes to practice and policy.

- Population and public health: Research with the goal of improving the health of the whole population, or defined subpopulations, through a better understanding of the ways in which social, cultural, environmental, occupational and economic factors determine health status. This category also focuses on prevention.

The types of achievements eligible for the award are described in Box 1.

A review panel was formed that comprised eminent health researchers, health care professionals and other stakeholders in health research from Canada and abroad. The panel assessed and ranked the applications using prespecified evalu-
Sharon Straus is with the LiKaShing Knowledge Institute, St. Michael's Hospital, University of Toronto, Toronto, Ont.; Chaidwick Leneis is Senior Knowledge Synthesis and Exchange Specialist, Canadian Institutes of Health Research, Ottawa, Ont.; and Ian Graham is Vice-President of Knowledge Translation, Canadian Institutes of Health Research.

Cite as CMAJ 2009. DOI:10.1503/cmaj.091593

All editorial matter in CMAJ represents the opinions of the authors and not necessarily those of the Canadian Medical Association. 
Box 1: Achievements eligible for the CIHR/CMAJ Top Canadian Achievements in Health Research award'

- Significant advance in the knowledge within a particular health or health research field that has promoted new advances in the field.

- Significant contribution that has addressed the needs of the general (or a vulnerable) health population.

- Development of a medical device or tool that has greatly enhanced diagnosis, patient care, recovery or treatment.

- Research or work that resulted in changes and improvements in the health of Canadians, health services or products, or the health care system (policy or practice) nationally or internationally.

- Study methodologies that have advanced research nationally and internationally, including developments in clinical epidemiology (e.g., advances in clinical trials and in systematic review methodologies).

ation criteria and the CIHR's numeric rating system. ${ }^{1} \mathrm{Mem}-$ bers of the CMAJ staff did not participate in this review process, but some were involved as observers.

From the 8 winners of the 2008/09 competition, CMAJ has chosen to publish the essays of the top two ranked achievements. The first is about a randomized trial of male circumcision to prevent HIV transmission. ${ }^{4}$ The other is about a citywide strategy to optimize the care of patients with myocardial infarction. ${ }^{5}$ Both of these essays highlight research that affects outcomes important to the public, and both have had an international impact. Summaries of the other 6 essays are available at www.cmaj.ca/cgi/doi/10.1503/cmaj.091624.

The 2009/10 competition for the CIHR/CMAJ Top Canadian Achievements in Health Research will be launched Sept. 30, 2009 (www.cihr-irsc.gc.ca/e/40251.html). In addi- tion to having the applications assessed by the review panel, we will post the top nominees on the $C M A J$ website in early 2010 and invite readers to vote for their favourite achievement. We look forward to sharing these amazing achievements with you next year.

Competing interests: Sharon Straus is the section editor of reviews at CMAJ but was not involved in the editorial decision-making process for this article. No competing interests were declared by Chaidwick Leneis or Ian Graham.

Contributors: All of the authors contributed substantially to the writing of this article and approved the final version submitted for publication.

Acknowledgements: This initiative is a joint partnership between CMAJ and the Canadian Institutes of Health Research (CIHR). CIHR provided in-kind support for the development of the initiative and completion of peer review of the applications. CMAJ provided in-kind support for the development of the initiative and the development of the peer-review process, as well as for the review and publication of the selected essays.

\section{REFERENCES}

1. Top Canadian Achievements in Health Research. Ottawa: Canadian Institutes of Health Research; 2008. Available: www.cihr-irsc.gc.ca/e/37888.html (accessed 2009 Sept. 8).

2. Domestic spending on research and development (GERD). Ottawa $(\mathrm{ON})$ : Statistics Canada; available: www40.statcan.gc.ca/101/cst01/scte03-eng.htm (accessed 2009 Aug. 21).

3. Canadian Institues of Health Research. Health research roadmap: creating innovative research for better health and healthcare. CIHR's Strategic Plan 2009/10 2013/14. Ottawa (ON): The Institutes; 2009. Available: www.cihr-irsc.gc.ca/e /documents/cihr_draft_strategic_plan_2009-2014_e.pdf (accessed 2009 Sept. 3).

4. Moses S. Male circumcision: a new approach to reducing HIV transmission. CMAJ 2009. DOI: $10.1503 / \mathrm{cmaj} .090809$.

5. Le May M. Code STEMI: implementation of a city-wide program for rapid assessment and management of myocardial infarction. CMAJ 2009. DOI:10.1503/cmaj.091087.

Correspondence to: Dr. Sharon E. Straus, LiKaShing Knowledge Institute, St. Michael's Hospital, University of Toronto, Toronto ON M5B 1W8; fax416 864-5805; sharon.straus@utoronto.ca 